\title{
The State of Morning Report in the Current Healthcare Landscape: a National Survey of Internal Medicine Program Directors
}

\author{
Juan N. Lessing, M.D. ${ }^{7}\left(\mathbb{D}\right.$, Kelly McGarry, M.D. ${ }^{2}$, Fred Schiffman, M.D. ${ }^{2}$, \\ Matthew Austin, M.D. ${ }^{3}$, Mark Hepokoski, M.D. ${ }^{4}$, Angela Keniston, MSPH', \\ Dominick Tammaro, M.D. ${ }^{2}$, and Kathleen M. Finn, M.D., M.Phil
}

\begin{abstract}
'Division of Hospital Medicine, Department of Medicine, Anschutz Medical Center, University of Colorado School of Medicine, Aurora, CO, USA; ${ }^{2}$ Department of Medicine, Alpert Medical School at Brown University, Providence, RI, USA; ${ }^{3}$ Department of Medicine, Yale University School of Medicine, New Haven, CT, USA; ${ }^{4}$ Department of Medicine, University of California San Diego School of Medicine, CA and the VA San Diego Healthcare System, San Diego, CA, USA; ${ }^{5}$ Department of Medicine, Massachusetts General Hospital, Harvard Medical School, Boston, MA, USA.
\end{abstract}

BACKGROUND: Case-based Morning Report (MR) has long been the predominant educational conference in Internal Medicine (IM) residency programs. The last comprehensive survey of IM MR was in 1986. Much has changed in the healthcare landscape since 1986 that may impact MR.

OBJECTIVE: We sought to determine the current state of MR across all US IM programs.

DESIGN: In 2018, US IM program directors (PDs) were surveyed about the dynamics of MR at their institutions, perceived pressures, and realized changes.

KEY RESULTS: The response rate was 70.2\% (275/392). MR remains highly prevalent (97.5\% of programs), although held less frequently (mean 3.9 days/week, SD 1.2), for less time (mean $49.4 \mathrm{~min}$, SD 12.3), and often later in the day compared to 1986 . MR attendees have changed, with more diversity of learners but less presence of educational leaders. PD presence at MR is associated with increased resident attendance (high attendance: $78 \%$ vs $61 \%, \mathrm{p}=0.0062$ ) and punctuality (strongly agree/ agree: $59 \%$ vs 43\%, p=0.0161). The most cited goal for MR is utilizing cases to practice clinical reasoning. Nearly $40 \%$ of PDs feel pressure to move or cancel MR; of those, $61.2 \%$ have done so, most commonly changing the timing (48.5\%), reducing the length (18.4\%), and reducing the number of sessions per week (11.7\%). Compared to community-based and to community-based, universityaffiliated programs, university-based programs have 2.9 times greater odds (95\% CI: 1.3, 6.9; $\mathrm{p}=0.0081)$ and 2.5 times greater odds (95\% CI 1.5, 4.4; $\mathrm{p}=0.0007)$, respectively, of holding MR after $9 \mathrm{AM}$, and 1.8 times greater odds (95\% CI: $0.8,4.2 ; \mathrm{p}=0.1367)$ and 2.0 times greater odds (95\% CI: 1.2, 3.5; $\mathrm{p}=0.0117$ ), respectively, of reporting pressure to cancel or move MR compared to their counterparts.

CONCLUSIONS: While MR ubiquity reflects its continued perceived value, PDs have modified MR to accommodate

Portions of our findings were presented as a poster at the Association of Program Directors in Internal Medicine (APDIM) Fall Meeting, Denver, CO, October 17-19, 2019.

Received February 16, 2021

Accepted June 24, 2021

Published online September 28, 2021 changes in the healthcare environment. This includes reduced frequency, shorter length, and moving conferences later in the day. Additional studies are needed to understand how these changes impact learning.

KEY WORDS: morning report; medical education; graduate medical education; internal medicine residency; program director; undergraduate medical education.

J Gen Intern Med 37(7):1665-72

DOI: $10.1007 / \mathrm{s} 11606-021-07010-1$

(c) Society of General Internal Medicine 2021

\section{INTRODUCTION}

Case-based conference, traditionally called Morning Report (MR) or Resident Report, has been the predominant educational conference for internal medicine (IM) residency programs in the US for more than 50 years [1-3]. MR was conducted at $98 \%$ of programs in 1986 when last comprehensively surveyed [4] and has been consistently described as one of the most valued educational experiences by trainees [5-7]. The purpose and format of MR has varied over time [1]. A 2013 literature review of MR noted heterogenous purposes, methods, and settings, and concluded that residency programs should tailor MR to their own education needs [2]. A recent study on the content of MR at several Veterans Administration hospitals [8] also confirmed a wide variety of formats at similar type programs. Since the last comprehensive surveys of IM residency program MR in 1986 $[4,9,10]$, much has changed in the healthcare environment that impacts resident education, including mandated resident work hour rules and shortening length of stay (LOS) with pressure for high patient throughput [11]. The impact of these healthcare changes on MR is not known. We hypothesize that these changes impacted important characteristics of MR, such as timing, content, and quantity. To test this hypothesis, we conducted a national survey of residency program directors (PDs) in IM focused on current MR format, purpose, and dynamics as well as perceived pressures and changes made to MR in response to these pressures. 


\section{METHODS}

\section{Study Settings and Participants}

The Association of Program Directors in Internal Medicine (APDIM) is a professional association within the Alliance for Academic Internal Medicine (AAIM) that represents leaders in graduate medication education (GME). The APDIM Survey and Scholarship Committee conducts a yearly national survey of PDs to get their insights on topics pertinent to GME. The 2018 survey was emailed on August 1st, 2018, to 392 APDIM member residency programs with American College of Graduate Medical Education (ACGME) accreditation.

\section{Instrument}

The survey methods, conducted similarly since 2008 , have been previously described [12]. Questions specific to MR were pretested and revised by the APDIM Survey and Scholarship Committee, pilot-tested for content validity by AAIM's Research Committee (consisting of experts in GME), and revised further (see Appendix). The study (\#18-AAIM-101) was deemed exempt by Pearl IRB (U.S. DHHS \#IRB00007772).

Survey instructions stated " 'Morning Report' refers to any conference attended by learners that is separate from a traditional lecture series or morbidity and mortality conferences. 'Morning Report' is used in the broadest sense here, recognizing that the conference might not be held in the morning and that it might not only be case-based." Reminder requests were emailed to PDs copying the program administrator. Committee members sent personal reminder emails to nonresponders until survey closure on November 30th, 2018.

\section{Statistical Analysis}

Data analysis was conducted using Stata 14.2 (StataCorp LP, College Station, TX) and SAS Enterprise Guide 8.1 (SAS
Institute, Inc., Cary, NC). Before de-identifying final responses, the study population dataset was appended with external sources, including US Census Bureau data for geographic region [13]. Residency program characteristics were obtained from the ACGME Accreditation Database System [14]. Program type and other characteristics were obtained through a data license provided by the American Medical Association Fellowship and Residency Electronic Interactive Database Access System [15].

Descriptive statistics for analysis included the reporting of frequencies and percentages for categorical variables and measures of central tendency (e.g., mean, median, standard deviation) for continuous variables. To test for goodness-of-fit or statistical associations between categorical variables, we used the adjusted Wald (Pearson) test of association (a test statistic more sensitive for survey populations with multiple characteristics that might explain variance). We used the Mann-Whitney (Wilcoxon) test to compare means of continuous variables (due to nonparametric distributions) to dichotomous variables. To describe statistical representativeness of survey responses, essential characteristics of respondents and their programs were compared to the overall survey population using variables from third-party data sources described above. Statistical significance was designated using an alpha level of 0.05 . From free-text responses, themes with representative examples were identified by the authors (JL and AK) via an inductive approach using conventional content analysis [16].

\section{RESULTS}

Out of 465 IM programs, 392 are APDIM members and survey-eligible. The survey response rate is $70.2 \%$ (275/392). There are no statistical differences based on core characteristics between respondents and non-respondents (Table 1). Although

Table 1 Core Characteristics of Responding and Nonresponding Internal Medicine Residency Programs: 2018 Survey of US Internal Medicine Residency Program Directors

\begin{tabular}{|c|c|c|c|c|}
\hline & $\begin{array}{l}\text { Respondents } \\
\mathbf{N}=\mathbf{2 7 5}\end{array}$ & $\begin{array}{l}\text { Non-respondents } \\
N=117\end{array}$ & $\begin{array}{l}\text { Total } \\
N=392\end{array}$ & \\
\hline & No. (column \%) & No. (column \%) & No. (column \%) & P-value* \\
\hline \multicolumn{5}{|l|}{ Program type (AMA-FREIDA) } \\
\hline University-based & $98(35.6)$ & $29(24.8)$ & $127(32.4)$ & 0.059 \\
\hline Community-based & $37(13.5)$ & $18(15.4)$ & $55(14.0)$ & 0.664 \\
\hline Community-based, university-affiliated & $134(48.7)$ & $68(58.1)$ & $202(51.5)$ & 0.155 \\
\hline Military-based & $6(2.2)$ & $2(1.7)$ & $8(2.0)$ & 0.578 \\
\hline \multicolumn{5}{|l|}{ Census region (US Census Bureau)** } \\
\hline Northeast & $85(31.1)$ & $36(31.0)$ & $121(31.1)$ & 0.986 \\
\hline Midwest & $59(21.6)$ & $32(27.6)$ & $91(23.4)$ & 0.375 \\
\hline West & $41(15.0)$ & $16(13.4)$ & $57(14.7)$ & 0.730 \\
\hline South & $88(32.2)$ & $32(27.6)$ & $120(30.9)$ & 0.393 \\
\hline VA affiliation: Yes (ACGME) & $102(37.1)$ & $32(27.4)$ & $134(34.2)$ & 0.143 \\
\hline & Mean (SD) & Mean (SD) & Mean (SD) & P-value $* * *$ \\
\hline Program size: No. ACGME approved positions & $68.3(42.1)$ & $62.5(36.5)$ & $66.5(40.5)$ & 0.438 \\
\hline Program director tenure as of 2018 (years; ACGME) & $5.9(6.2)$ & $7.1(6.9)$ & $6.3(6.5)$ & 0.147 \\
\hline
\end{tabular}

AMA-FREIDA, American Medical Association Residency and Fellowship Database; ACGME, Accreditation Council for Graduate Medical Education; ABIM, American Board of Internal Medicine; VA, Veterans Affairs; SD, standard deviation.

*Bivariate (adjusted Wald [Pearson]) test of association with one degree of freedom used for categorical variables: alpha $=0.05$.

**Excludes programs from three US territories, due to small cell sizes/data confidentiality.

***Mann-Whitney (nonparametric) test for difference in means: alpha=0.05. 
Table 2 Survey Results by Type of Residency Program

\begin{tabular}{|c|c|c|c|c|}
\hline & $\begin{array}{l}\text { All programs } \\
\mathrm{N}=275\end{array}$ & $\begin{array}{l}\text { University-based } \\
\mathrm{N}=98\end{array}$ & $\begin{array}{l}\text { Community-based } \\
\mathbf{N}=\mathbf{3 7}\end{array}$ & $\begin{array}{l}\text { Community-based, } \\
\text { university-affiliated } \\
\mathrm{N}=134\end{array}$ \\
\hline & No. (column \%) & No. (column \%) & No. (column \%) & No. (column \%) \\
\hline Yes, our residency program has morning report? & $268(97.5)$ & $98(100)$ & $35(94.6)$ & $129(96.3)$ \\
\hline $\begin{array}{l}\text { How many days per week is morning report } \\
\text { held? }\end{array}$ & Mean 3.9 (SD 1.2) & Mean 3.8 (SD 1.2) & Mean $4.2(\mathrm{SD} 1.4)$ & Mean 3.8 (SD 1.2) \\
\hline 1 day & $10(3.7)$ & $5(5.1)$ & $2(5.7)$ & $3(2.3)$ \\
\hline 2 days & $29(10.8)$ & $8(8.2)$ & $3(8.6)$ & $18(14.0)$ \\
\hline 3 days & $51(19.0)$ & $19(19.4)$ & $2(5.7)$ & $30(23.3)$ \\
\hline 4 days & $84(31.3)$ & $36(36.7)$ & $11(31.4)$ & $34(26.4)$ \\
\hline 5 days & $85(31.7)$ & $27(27.6)$ & $14(40.0)$ & $41(31.8)$ \\
\hline 6 days & $1(0.4)$ & $1(1)$ & $0(0)$ & $0(0)$ \\
\hline 7 days & $5(1.9)$ & $2(2)$ & $2(5.7)$ & $1(0.8)$ \\
\hline Other & $3(1.1)$ & $0(0)$ & $1(2.9)$ & $2(1.6)$ \\
\hline For how long does morning report last? & Mean 49.4 (SD 12.3) & Mean 51.3 (SD 11.4) & Mean 47.6 (SD 12.3) & Mean 48.5 (SD 12.2) \\
\hline 30 minutes & $53(19.8)$ & $13(13.3)$ & $9(25.7)$ & $28(21.7)$ \\
\hline 45 minutes & $90(33.6)$ & $33(33.7)$ & $11(31.4)$ & $45(34.9)$ \\
\hline 60 minutes & $122(45.5)$ & $51(52.0)$ & $15(42.9)$ & $55(42.6)$ \\
\hline 90 minutes & $3(1.1)$ & $1(1.0)$ & $0(0)$ & $1(0.8)$ \\
\hline More than 90 minutes & $0(0)$ & $0(0)$ & $0(0)$ & $0(0)$ \\
\hline \multicolumn{5}{|l|}{ On most days, when is morning report held? } \\
\hline Early morning (before 9am) & $163(60.8)$ & $45(45.9)$ & $25(71.4)$ & $88(68.2)$ \\
\hline Late morning (after 9am) & $28(10.4)$ & $13(13.3)$ & $1(2.9)$ & $14(10.9)$ \\
\hline Mid-day & $55(20.5)$ & $30(30.6)$ & $6(17.1)$ & $18(14.0)$ \\
\hline Early afternoon & $14(5.2)$ & $7(7.1)$ & $3(8.6)$ & $4(3.1)$ \\
\hline Late afternoon & $3(1.1)$ & $3(3.1)$ & $0(0)$ & $3(2.3)$ \\
\hline The time varies & $5(1.9)$ & $0(0)$ & $0(0)$ & $2(1.6)$ \\
\hline \multicolumn{5}{|l|}{ Frequently conduct/lead morning report } \\
\hline Chief residents & $166(61.9)$ & $77(78.6)$ & $14(40.0)$ & $70(54.3)$ \\
\hline Senior residents & $79(29.5)$ & $27(27.6)$ & $15(42.9)$ & $36(27.9)$ \\
\hline Junior residents & $40(14.9)$ & $14(14.3)$ & $9(25.7)$ & $17(13.2)$ \\
\hline Faculty & $75(28)$ & $15(15.3)$ & $12(34.3)$ & $47(36.4)$ \\
\hline Program Director/Associate Program Director & $65(24.3)$ & $14(14.3)$ & $9(25.7)$ & $41(31.8)$ \\
\hline Chair of medicine & $19(7.1)$ & $4(4.1)$ & $1(2.9)$ & $14(10.9)$ \\
\hline Fellows & $1(0.4)$ & $0(0)$ & $1(2.9)$ & $0(0)$ \\
\hline Other & $1(0.4)$ & $0(0)$ & $1(2.9)$ & $0(0)$ \\
\hline \multicolumn{5}{|l|}{ Program director attends morning report } \\
\hline Always & $69(25.7)$ & $25(25.5)$ & $8(22.9)$ & $32(24.8)$ \\
\hline Frequently & $92(34.3)$ & $39(39.8)$ & $13(37.1)$ & $38(29.5)$ \\
\hline Sometimes & $79(29.5)$ & $29(29.6)$ & $7(20.0)$ & $43(33.3)$ \\
\hline Rarely & $22(8.2)$ & $3(3.1)$ & $5(14.3)$ & $14(10.9)$ \\
\hline Never & $5(1.9)$ & $1(1.0)$ & $2(5.7)$ & $2(1.6)$ \\
\hline Missing/Not Applicable & $1(0.4)$ & $1(1.0)$ & $0(0)$ & $0(0)$ \\
\hline \multicolumn{5}{|l|}{ Chair of medicine attends morning report } \\
\hline Always & $8(3.0)$ & $1(1.0)$ & $1(2.9)$ & $6(4.7)$ \\
\hline Frequently & $30(11.2)$ & $14(14.3)$ & $1(2.9)$ & $12(9.3)$ \\
\hline Sometimes & $63(23.5)$ & $27(27.6)$ & $4(11.4)$ & $30(23.3)$ \\
\hline Rarely & $51(19.0)$ & $26(26.5)$ & $9(25.7)$ & $15(11.6)$ \\
\hline Never & $86(32.1)$ & $30(30.6)$ & $11(31.4)$ & $45(34.9)$ \\
\hline Missing/Not Applicable & $30(11.2)$ & $0(0)$ & $9(25.7)$ & $21(16.3)$ \\
\hline \multicolumn{5}{|l|}{ Morning report attendance is high } \\
\hline Strongly Agree & $92(34.3)$ & $33(33.7)$ & $15(42.9)$ & $41(31.8)$ \\
\hline Agree & $99(36.9)$ & $31(31.6)$ & $14(40.0)$ & $52(40.3)$ \\
\hline Neutral & $45(16.8)$ & $20(20.4)$ & $5(14.3)$ & $20(15.5)$ \\
\hline Disagree & $27(10.1)$ & $13(13.3)$ & $0(0)$ & $14(10.9)$ \\
\hline Strongly Disagree & $4(1.5)$ & $1(1.0)$ & $1(2.9)$ & $2(1.6)$ \\
\hline Missing/Not Applicable & $1(0.4)$ & $0(0)$ & $0(0)$ & $0(0)$ \\
\hline \multicolumn{5}{|c|}{ Residents (PGY-2 and PGY-3) are usually on time for morning report } \\
\hline Strongly Agree & $34(12.7)$ & $9(9.2)$ & $7(20.0)$ & $17(13.2)$ \\
\hline Agree & $106(39.6)$ & $38(38.8)$ & $16(45.7)$ & $48(37.2)$ \\
\hline Neutral & $49(18.3)$ & $18(18.4)$ & $7(20.0)$ & $24(18.6)$ \\
\hline Disagree & $62(23.1)$ & $27(27.6)$ & $4(11.4)$ & $31(24.0)$ \\
\hline Strongly Disagree & $14(5.2)$ & $6(6.1)$ & $1(2.9)$ & $7(5.4)$ \\
\hline Missing/Not Applicable & $3(1.1)$ & $0(0)$ & $0(0)$ & $2(1.6)$ \\
\hline
\end{tabular}

there is slight over-representation of university-based programs, this difference is not statistically significant.

General MR characteristics are reported in Table 2 and Intern Report characteristics are reported in Table 3. MR remains highly prevalent, and $97.5 \%$ of programs continue to hold MR. Only one program reported not having MR and six reported previously having MR but cancelling it.

Most programs, $63 \%$, convene MR 4 or 5 days a week, average 3.9 (SD 1.2). Only $39.6 \%$ of programs have a distinct intern report, mostly held once per week. MR length varies, but 
Table 3 Survey Results about Intern Report by Type of Residency Program

\begin{tabular}{|c|c|c|c|c|}
\hline & $\begin{array}{l}\text { All programs } \\
N=268\end{array}$ & $\begin{array}{l}\text { University-based } \\
\mathrm{N}=98\end{array}$ & $\begin{array}{l}\text { Community-based } \\
\mathbf{N}=35\end{array}$ & $\begin{array}{l}\text { Community-based, } \\
\text { university-affiliated } \\
\mathrm{N}=129\end{array}$ \\
\hline & No. (column \%) & No. (column \%) & No. (column \%) & No. (column \%) \\
\hline $\begin{array}{l}\text { Yes, our residency program has a separate } \\
\text { intern report? }\end{array}$ & $106(39.6)$ & $51(52.0)$ & $8(22.9)$ & $47(36.4)$ \\
\hline $\begin{array}{l}\text { Of those with a separate intern report, how } \\
\text { many days per week is intern report held? }\end{array}$ & Mean $1.4(\mathrm{SD} 1.1)$ & Mean $1.3(\mathrm{SD} 0.6)$ & Mean $2.4(\mathrm{SD} 2.6)$ & Mean $1.5(\mathrm{SD} 1.3)$ \\
\hline 1 day & $75(70.8)$ & $39(76.5)$ & $3(37.5)$ & $33(70.2)$ \\
\hline 2 days & $14(13.2)$ & $9(17.6)$ & $1(12.5)$ & $4(8.5)$ \\
\hline 3 days & $4(3.8)$ & $3(5.9)$ & $0(0)$ & $1(2.1)$ \\
\hline 4 days & $0(0)$ & $0(0)$ & $0(0)$ & $0(0)$ \\
\hline 5 days & $2(1.9)$ & $0(0)$ & $0(0)$ & $2(4.3)$ \\
\hline 6 days & $0(0)$ & $0(0)$ & $0(0)$ & $0(0)$ \\
\hline 7 days & $2(1.9)$ & $0(0)$ & $1(12.5)$ & $1(2.1)$ \\
\hline Other & $9(8.5)$ & $0(0)$ & $3(37.5)$ & $6(12.8)$ \\
\hline Missing & $0(0)$ & $0(0)$ & $0(0)$ & $6(12.8)$ \\
\hline
\end{tabular}

the average length is $49 \mathrm{~min}$ (SD 12), compared to $54 \mathrm{~min}$ in 1986 [4]. One-third of programs report MR length is $45 \mathrm{~min}$ and one-fifth have MR for $30 \mathrm{~min}$. Time of day MR is held also varies; $60.8 \%$ hold MR early morning (defined as before 9AM), $10.4 \%$ in the late morning, and $20.5 \%$ at mid-day. Six percent of programs hold MR in the afternoon. University-based programs are more likely to hold MR later (after 9AM) compared to community-based programs and to community-based, university-affiliated programs, with 2.9 times greater odds (95\% CI: $1.3,6.9 ; \mathrm{p}=0.0081$ ) and 2.5 times greater odds respectively (95\% CI: $1.5,4.4 ; \mathrm{p}=0.0007)$.

PDs report participants who most commonly attend are Post-Graduate Year (PGY)-2 and higher residents (94.4\%). Many programs also invite interns (PGY-1) (81\%) and medical students $(72.7 \%)$. PD participation varies from $25.7 \%$ of PDs indicating they always attend, $34.3 \%$ frequently attend, and $29.5 \%$ sometimes attend. A minority (14.2\%) of PDs report their chairs of medicine always or frequently attend. Inviting patients is very infrequent: $80.6 \%$ programs said patients are not invited.

Chief medical residents (CMRs) and senior residents most often conduct or lead MR. CMRs are more likely to lead MR at university-based compared to community-based programs (79\% vs $42 \%$, p $<0.001$ ).

All programs indicate most MR sessions are case-based (mode $100 \%$, mean $87.4 \%$, SD 18.8). The most often cited goals of MR are develop clinical reasoning (97.4\%), increase residents' knowledge $(80.2 \%)$, and teach acute management $(65.3 \%)$. Thematic and representative examples of responses to what is special about your MR are listed in Table 4. Just over half of PDs, $58.8 \%$, report the goals of MR do not change throughout the academic year. For the rest, the most frequent free-text answers indicate MR starts the year with fundamentals ("bread and butter cases"), then moves focus as the year progresses towards management and clinical reasoning. Half $(50.7 \%)$ of programs schedule time to follow-up previously discussed cases. Less than half $(41.4 \%)$ of programs provide refreshments and even fewer (19.4\%) provide pager coverage for house staff. The vast majority of PDs believe their residents are comfortable speaking at MR (91.8\%) but less so for interns $(77.6 \%)$. Nearly three-quarters of PDs (71.2\%) believe attendance is high and nearly half (52.3\%) agree that residents are "usually on time." The frequent presence of the PD at MR is associated with increased resident attendance ( $78 \%$ vs $61 \%$, $\mathrm{p}=0.0062$ ) and showing up on time ( $59 \%$ vs $43 \%, \mathrm{p}=0.0161$ ).

Notably, 38.4\% of PDs report feeling pressured to cancel or move MR in response to hospital clinical demands. Of these, $51.5 \%$ report feeling moderate or very pressured to cancel MR. Over half (61.2\%) made change(s) to MR in response to hospital pressure. The most common changes were changing the time (48.5\%), reducing the length of MR (18.4\%), and reducing the number of MR sessions (11.7\%). Universitybased programs have a 1.8 times greater odds (95\% CI: 0.8 , $4.2 ; \mathrm{p}=0.1367$ ) compared to community-based programs of reporting pressure to move or cancel MR and a 2.0 times greater odds (95\% CI: $1.2,3.5 ; \mathrm{p}=0.0117)$ compared to community-based, university-affiliated programs.

\section{DISCUSSION}

To the best of our knowledge, this is the first nation-wide survey of the state of IM MR including all program- and hospital-types since the 1980s. Our results confirm that even after nearly four decades the vast majority of programs continue to hold MR, which suggests it is still highly valued as an educational venue. Our results also suggest that time and pressures of the healthcare environment have impacted MR.

Duration/Timing/Frequency. Historically, MR at the majority of programs lasted $1 \mathrm{~h}$ [9]. Our survey finds MR duration at more than half of programs is now $45 \mathrm{~min}$ or less. These changes may reflect the evolution of the purpose of MR from a time when MR served as a daily "intake" census for all admitted patients $[3,9]$ to current practice where usually one or two cases are presented [8]. Shifting house staff preferences or adaptation to learning theories about shorter optimal timespans could also be playing a role. 
The MR name highlights its morning origins but the data suggests it is being pushed to later in the day. While the majority of programs continue to have MR in the morning, nearly $40 \%$ have moved MR to later, with one-fifth of programs holding MR mid-day. In contrast, in $198672 \%$ of programs held MR before 9:15AM [9]. The noon-hour MR trend is particularly noteworthy, as well as a possible concerning trend. Traditionally, many programs had MR in the morning and a separate, often lecture-based, lunchtime conference. These two didactics served important but distinct roles. Moving MR to the lunch hour begs the question whether these two conferences have merged or one has subsumed the other, suggesting the possibility of reduced time for educational conferences.

The same trends hold when it comes to MR frequency. MR used to be a daily activity. In 1986, the majority of programs held MR five or more times per week (average 5.6, SD 1.3) and nearly $40 \%$ even had MR on weekends. This is no longer the case. Today, just above $60 \%$ of programs hold MR four-to-five times per week (average 3.9, SD 1.2). As other demands pile up, or perhaps priorities shift, MR has become a less frequent occurrence.

Our survey cannot confirm a direct cause-and-effect. But the overwhelming trend towards later, shorter, and less frequent MR all point to a rapidly changing learning environment, and seemingly one that gives less emphasis, or at least less time, to MR. PD free-text answers point to hospital pressures including on rounding time and emphasis on discharge as important drivers. As nearly $40 \%$ of PDs report hospital pressure to move or shorten MR, the result of these pressures may play a significant role.

While these trends appear across the board, their impact does not appear to be felt evenly throughout IM residency programs. University-based programs report being more affected, with an increased likelihood of holding MR later in the day compared to their community-based and communitybased, university-affiliated programs. Our survey cannot distinguish specific reasons for this discrepancy, but points to a difference in either pressures or reaction to these pressures based on program type.

Pressures to Cancel or Move MR. Perhaps our most important finding is the impact that hospital clinical demands have had on MR. Nearly $40 \%$ of PDs report perceived pressure from the hospital to outright cancel, push to later in the day, and/or shorten the timing MR (Table 5). While we did not survey PDs about reasons for this pressure, written comments suggest high volume patient days and pressure on rounding play a role. PDs who cancelled MR report work hours as a factor. It is very likely limited work hours and

Data extracted from published figures in Schiffman $1990^{9}$ using WebPlotDigitizer v4.4 (Rohatgi, Ankit, https://automeris.io/WebPlotDigitizer, Pacifica, California). reductions in LOS with resulting high patient throughout impact MR. This may explain why university-based programs - which may have higher patient volumes [17] — report more perceived pressure and have made more changes. Of those that report perceived pressure, nearly two-thirds of programs made changes, most commonly changing the MR time, or, less often, reducing its length. The impetus driving this sentiment - that time dedicated for learning and time spent on patient care are in conflict-is not new [18]. However, changing the time of MR due to hospital pressures may have educational cost without the intended benefit. One study observed that the change of MR to the afternoon made no difference on patient discharge time. In that same survey, three-quarters of their house staff said they preferred the morning MR time slot [19].

In addition, there are many other factors that impact medical education and residency training which may exert pressure on MR, including the role of supervision and autonomy. Future studies could explore the roles that these and other factors may play.

Who Attends. MR continues to serve principally PGY-2 residents and higher - with the vast majority of programs indicating residents frequently attend. Compared to the $1986 \mathrm{MR}$ survey, however, additional attendees have changed; in 1986, the majority of chairs of medicine regularly attended MR, while only $58 \%$ of interns and half of medical students participated $[9,10]$. This has near flipped - now a minority $(14 \%)$ of chairs attend, but $81 \%$ of interns and $72 \%$ of medical students join MR. We do not know how these changes impact the learning experience or outcome. Does the lack of attendance by the department chair or the PD send a signal that MR is less important or change how clinical reasoning is taught? Are trainees more comfortable speaking in the absence of senior faculty? Further study of these factors is needed.

Who Runs MR. Who leads MR depends highly on program type. University-based programs are nearly twice as likely to have a CMR lead MR than community-based programs (79\% vs $42 \%, \mathrm{p}<0.001)$. That a third of programs have senior residents facilitate MR may be reflective of programs with fewer CMRs, programs with PGY3 CMRs, or different educational goals for senior residents.

Educational Goals and Value of MR. There continue to be myriad purposes and goals of MR. However, what is cited by nearly all programs is the goal to "develop clinical reasoning," similar to prior surveys. Other goals most programs frequently cite are to increase residents' knowledge (content-driven), teach acute management, teach fundamentals early in the year, and teach evidence-based medicine literature review. Clearly, the survey results indicate most PDs value MR as a teaching tool, which is also in line with resident beliefs from earlier surveys $[5,6]$. Interestingly, only a small percentage 
Table 4 Most Cited Goals and Thematic Examples of Unique or Special Aspects of Morning Report from Free-Response Questions

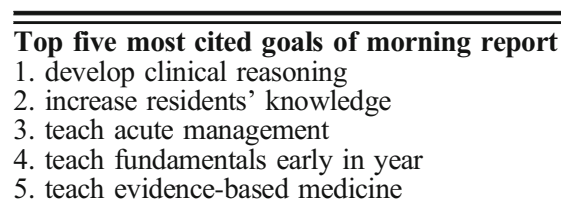

What do you consider the most unique/special aspect of your MR?

- Chief resident-led, resident-run

- emphasis on clinical reasoning

- variety of formats

- positive learning environment

- practice for residents-as-teacher

- interactive and case-based

- opportunity for PD to interact closely with residents

Numerous comments also pointed to seemingly contradictory MR strengths:

including interns

- Collegiality-building between resident and interns

-Interns bonding with residents

\section{presence of faculty}

- Presence of faculty to advance discussion

-Faculty discussants are present to add additional teaching points

-At least part of our program leadership (PD, APDs, core faculty) is present

almost every day

-Always supervised/run by faculty. Great teaching results!

-Clinical wisdom from experienced faculty in the back

-the faculty always take charge of the discussion

established cases with definite answer

- Clear established case

-established cases with clear diagnoses

-The case is not a fresh case and therefore there is time for adequate digestion and a teaching point and board style questions accompanies each excluding interns

- Opportunity to separate residents from interns

-Separate interns from juniors and seniors

\section{absence of faculty}

- Absence of faculty who dominate conversation

-chief resident run and not many faculty there to dominate the conversation

-We try to make it resident driven
(5.5\%) of PDs said MR is where best to learn about rare diagnoses. This is in contrast to what observational studies have found actually occurs. In a review of 200 diagnoses discussed in MRs at 10 VA hospitals throughout the US, Heppe found that $43 \%$ of cases discussed were considered rare [8]. What is actually done at MR may not always align with what PDs feel ought to be the focus.

Given the purported value of MR, interruptions should be minimized and attendance maximized. Clinical volume of work and work hours as well as incentives may impact attendance and timeliness of arrival at MR. Our survey found only one-quarter of programs routinely cover resident pagers and just over half provide food or beverage, which can incentivize or reduce barriers to attendance [20]. We did not ask about other means to reduce interruptions or improve attendance, although PDs did comment on this in free-text answers, for example, stating the positive effect of free food, having faculty promote timeliness, and impact on attendance by condensing

Table 5 Survey Results about Pressure to Cancel or Move Morning Report by Type of Residency Program

\begin{tabular}{|c|c|c|c|c|}
\hline & $\begin{array}{l}\text { All programs } \\
\mathbf{N}=\mathbf{2 6 8} \\
\text { No. (column \%) }\end{array}$ & $\begin{array}{l}\text { University-based } \\
\mathbf{N}=\mathbf{9 8} \\
\text { No. (column \%) }\end{array}$ & $\begin{array}{l}\text { Community-based } \\
\mathbf{N}=\mathbf{3 5} \\
\text { No. (column \%) }\end{array}$ & $\begin{array}{l}\text { Community-based, } \\
\text { university-affiliated } \\
\mathbf{N}=129 \\
\text { No. (column \%) }\end{array}$ \\
\hline $\begin{array}{l}\text { Pressured to cancel or move morning report } \\
\text { in response to hospital clinical demands? }\end{array}$ & $103(38.4)$ & $47(48.0)$ & $12(34.3)$ & $42(32.6)$ \\
\hline \multicolumn{5}{|c|}{ Of those who report feeling pressured - how pressured have you felt to cancel or move morning report? } \\
\hline Very pressured & $18(17.5)$ & $8(17.0)$ & $2(16.7)$ & $7(16.7)$ \\
\hline Moderately pressured & $35(34.0)$ & $19(40.4)$ & $4(33.3)$ & $12(28.6)$ \\
\hline Somewhat pressured & $49(47.6)$ & $20(42.6)$ & $6(50.0)$ & $22(52.4)$ \\
\hline Missing/Not Applicable & $1(1)$ & $0(0)$ & $0(0)$ & $1(2.4)$ \\
\hline \multicolumn{5}{|c|}{ What change(s) have you made to morning report in response to hospital pressure? } \\
\hline Reduced the number of morning reports & $12(11.7)$ & $7(14.9)$ & $2(16.7)$ & $3(7.1)$ \\
\hline Changed the time & $50(48.5)$ & $28(59.6)$ & $5(41.7)$ & $17(40.5)$ \\
\hline Reduced the length of morning reports & $19(18.4)$ & $10(21.3)$ & $2(16.7)$ & $7(16.7)$ \\
\hline Limited which PGY level residents attend & $7(6.8)$ & $1(2.1)$ & $1(8.3)$ & $5(11.9)$ \\
\hline Limited which clinical service residents attend & $7(6.8)$ & $4(8.5)$ & $1(8.3)$ & $2(4.8)$ \\
\hline Other & $4(3.9)$ & $2(4.3)$ & $0(0)$ & $2(4.8)$ \\
\hline
\end{tabular}

Note: Totals may not add up to $100 \%$ as excluded military-based programs as these are only 6 total programs. 
didactic time to a dedicated education half-day. In our survey, more than $70 \%$ of PDs feel attendance is high although only slightly more than half report their residents usually arrive on time. We found that PD presence at MR is significantly associated with both resident attendance $(\mathrm{p}=0.0062)$ and showing up on time ( $\mathrm{p}=0.0161)$. This may, of course, reflect simply that when the PD is present he/she can more accurately report on attendance. But this may also suggest that for programs challenged by poor attendance or tardiness, having the PD or an associate PD commit to consistently attend may improve attendance and may enhance MR quality.

\section{LIMITATIONS}

Our study provides important insights into the current state of MR at IM residency programs; however, there are several limitations. First, this was a survey only of IM PDs. Our results are centered around IM programs and may not apply as well to other fields. Second, this reflects only the opinions of PDs and not residents, faculty, or hospital leadership. Many PDs attend MR sporadically and their answers may not reflect situational reality. Additional research on the perspective of other groups is warranted. Third, only IM programs who are members of AAIM were eligible to participate, so these results do not reflect all IM programs and especially some newer programs. However, given the large number of PDs surveyed across the country, these results likely reflect the state of most MRs, especially given there was no statistical important differences between respondents and non-respondents. Fourth, MR variation within a program may not be fully captured; IM programs that include more than one teaching site may have multiple MRs, and each site may vary what they do. For the sake of simplicity, we asked PDs to answer based on their largest MR site. Thus, we may have missed subtle differences at satellite hospitals. Fifth, while we provided an explicit definition of MR, it is possible respondents answered questions based on different understanding of MR or types of conferences. We also limited choices to reduce cognitive load of survey participants thus forcing answers about the timing of MR. Six, pressures external to the healthcare landscape or the opinion of learners were not directly queried. Finally, our survey was completed prior to the start of the COVID-19 epidemic. The need for social distancing impacted medical education and undoubtedly temporarily affected MR, which is not reflected in our data.

\section{CONCLUSIONS}

Despite these limitations, this study remains the most recent and comprehensive survey and analysis of MR throughout all IM residency programs in the US. Our results indicate that PDs clearly believe MR is a valuable educational endeavor and appear to struggle with continuing this educational venue within the demands of hospital operations and the healthcare landscape.

This survey provides better understanding of how and why MR has changed and how MR is being adapted to the current environment. Over many decades, MR remains ubiquitous, with nearly all programs holding it, but the duration, frequency, and its purposes have changed. University-based programs are more likely to have fewer and later MR than nonuniversity-based programs. Our hope is the survey results prove useful to PDs and medical educators in adapting MR in a deliberate and thoughtful manner rather than simply in response to changing pressures. Future studies are needed to reflect on both the perceptions of other stakeholders and the impact these changes have had on learning.

Acknowledgements: The authors wish to thank the staff of the Alliance for Academic Internal Medicine (AAIM) for their technical and administrative support, specifically Michael Kisielewski, M.A., AAIM Surveys and Research Manager, and Jordan M. Ortiz, B.S., AAIM Survey and Data Senior Specialist, and are grateful for the support of the Association of Program Directors of Internal Medicine (APDIM), the members of the APDIM Survey and Scholarship Committee, and the residency program directors who completed the survey. Dr. Lessing also wishes to acknowledge longstanding support in pursuing this project by Ken Steinberg, M.D.; Gurpreet Dhaliwal, M.D.; and Read Pierce, M.D.

Corresponding Author: Juan N. Lessing, M.D.; Division of Hospital Medicine, Department of Medicine, Anschutz Medical Center, University of Colorado School of Medicine, Aurora, CO, USA (e-mail: juan. lessing@cuanschutz.edu).

Supplementary Information: The online version contains supplementary material available at https://doi.org/10.1007/s11606-02107010-1.

\section{Declarations:}

Ethical Approval: This study and its protocol (Number: 18-AAIM-101) were submitted to Pearl IRB (registered with the US Department of Health and Human Services Office for Human Research Protections as IRB00007772) for exemption determination in accordance with FDA 21 CFR 56.104 and DHHS 45 CFR 46.101 regulations and were deemed exempt under 45 CFR 46.101(b) category 2.

\section{REFERENCES}

1. Amin Z, Guajardo J, Wisniewski W, et al. Morning report: focus and methods over the past three decades. Acad Med. 2000;75(10 Suppl):S1S5. doi:https://doi.org/10.1097/00001888-200010001-00002

2. McNeill M, Ali SK, Banks DE, et al. Morning report: can an established medical education tradition be validated?. J Grad Med Educ. 2013;5(3):374-84.

3. Parrino TA. The social transformation of medical morning report. $J$ Gen Intern Med. 1997;12(5):332-3.

4. Parrino TA, Villanueva AG. The principles and practice of morning report. JAMA. 1986;256(6):730-3.

5. Ways M, Kroenke K, Umali J, et al. Morning report. A survey of resident attitudes. Arch Intern Med. 1995;155(13):1433-7.

6. Gross CP, Donnelly GB, Reisman AB, et al. Resident expectations of morning report: a multi-institutional study. Arch Intern Med. 1999;159(16): 1910-4.

7. Albert TJ, Redinger $J$, Starks $H$, et al. Internal Medicine Residents' Perceptions of Morning Report: a Multicenter Survey. J Gen Intern Med. 2021;36(3):647-53. 
8. Heppe DB, Beard AS, Cornia PB, et al. A Multicenter VA Study of the Format and Content of Internal Medicine Morning Report. $J$ Gen Intern Med. 2020;35(12):3591-6.

9. Schiffman FJ, Mayo-Smith MF, Burton MD. Resident report: a conference with many uses. R I Med J. 1990;73(3):95-102.

10. Schiffman FJ. Morning report and work rounds: opportunities for teaching and learning. Trans Am Clin Climatol Assoc. 1996;107:275-86.

11. Emmerling SA, Fisher MC, McGarvey J. The Use of a Patient Discharge Lounge and the Impact on 30-Day Hospital Readmission. J Nurs Adm. 2020;50(11):590-7.

12. Chacko KM, Reddy S, Kisielewski M, et al. Postinterview Communications: Two Surveys of Internal Medicine Residency Program Directors Before and After Guideline Implementation. Acad Med. 2018;93(9): 136773. doi: https://doi.org/10.1097/ACM.0000000000002261.

13. U.S. Census Bureau. Census Regions and Divisions of the United States. [Online]. Available: https://www2.census.gov/geo/pdfs/maps-data/ maps/reference/us_regdiv.pdf. [Accessed December 2018].

14. Accreditation Council for Graduate Medical Education. Accreditation Database System Online (Public). [Online]. Available: https://apps. acgme.org/ads/Public/Programs/Search. [Accessed June 2018].
15. American Medical Association (AMA). "Fellowship and Residency Electronic Interactive Database Access System (FREIDA) Online." Data provided via a licensing agreement between AMA and the Alliance for Academic Internal Medicine. Also available online: https://freida.amaassn.org. [Obtained September 2018]

16. Hsieh HF, Shannon SE. Three approaches to qualitative content analysis. Qual Health Res. 2005;15(9):1277-88.

17. Zoorob R, Malpani V, Malpani S. Adult inpatient training for a family practice residency: a university-versus community-based setting. Fam Med. 2002;34(7):518-21.

18. Minichiello TM, Auerbach AD, Wachter RM. Caregiver perceptions of the reasons for delayed hospital discharge. Eff Clin Pract. 2001;4(6):250-5.

19. Campbell S, Campbell M, Shah C, et al. Educational Conference Scheduling, Patient Discharge Time, and Resident Satisfaction. J Grad Med Educ. 2014;6(3):574-6.

20. Cosimini MJ, Mackintosh L, Chang TP. Number needed to eat: pizza and resident conference attendance. Med Educ. 2016;50(12):1204-7.

Publisher's Note: Springer Nature remains neutral with regard to jurisdictional claims in published maps and institutional affiliations. 